(2) Open Access Full Text Article

\title{
Patients harboring EGFR mutation after primary resistance to crizotinib and response to EGFR- tyrosine kinase inhibitor
}

This article was published in the following Dove Press journal:

OncoTargets and Therapy

8 January 2016

Number of times this article has been viewed

\author{
Wenxian Wang' \\ Xiaowen Jiang' \\ Zhengbo Song',2 \\ Yiping Zhang',2 \\ 'Department of Chemotherapy, \\ Zhejiang Cancer Hospital, ${ }^{2}$ Key \\ Laboratory Diagnosis and Treatment \\ Technology on Thoracic Oncology, \\ Hangzhou, Zhejiang, People's Republic \\ of China
}

\begin{abstract}
Anaplastic lymphoma kinase (ALK) rearrangement lung cancer responds to ALK tyrosine kinase inhibitors. It is known that many cases ultimately acquired resistance to crizotinib. However, a case of primary resistance is rare. We present a case of harboring exon 19 deletion in epidermal growth factor receptor in ALK rearranged lung adenocarcinoma, who experienced a partial tumor response to icotinib after failure with crizotinib therapy and chemotherapy. Considering the partial response, we conclude that it is important to find the cause of resistance to crizotinib. We detected gene mutations with plasma by the next-generation sequencing; the next-generation sequencing demonstrates an attractive system to identify mutations improving the outcome of patients with a deadly disease.
\end{abstract}

Keywords: non-small cell lung cancer, anaplastic lymphoma kinase, crizotinib, epidermal growth factor receptor

\section{Introduction}

The EML4 gene and the $A L K$ gene rearrangements occur in $2 \%-7 \%$ of patients with non-small-cell lung cancer (NSCLC) overall. ${ }^{1}$ Crizotinib has already shown an impressive single-agent activity in $A L K$-positive lung adenocarcinomas (ADCs). In ADCs, an objective response rate to crizotinib is about $60 \%$ and its median progressionfree survival is nearly 10 months. ${ }^{2}$ However, it is known that many cases ultimately acquired resistance to crizotinib. ${ }^{3}$ Several second-generation $A L K$ inhibitors have been developed and are currently under evaluation in clinical trials. They have been shown to be effective for crizotinib-resistant patients, with response rates of $55 \%$ and $56 \% .4$ Nowadays, a case of primary resistance is rare, thus the mechanisms of primary resistance to ALK inhibitors for these patients are not well-known. In this report, we present a case of successful treatment of an $A L K$ rearrangement ADC patient transformed to epidermal growth factor receptor (EGFR) mutation with icotinib. Icotinib is a kind of EGFR-tyrosine kinase inhibitor (EGFR-TKI) that has shown effectiveness as therapy for advanced NSCLC with EGFR activating mutations, such as erlotinib and gefitinib. ${ }^{6}$ In a Phase IV study of icotinib, it illustrated a favorable toxicity profile and efficacy in EGFR-mutated patients. ${ }^{7}$

\section{Case report}

A 49-year-old female, who was a nonsmoker, presented to our hospital with 1 month history of cough. She provided informed verbal consent to participate in this study and this study was also approved by the Institutional Review Board of Zhejiang Cancer Hospital. Computed tomography (CT) scans revealed a mass at right lung and
Department of Chemotherapy, Zhejiang

Cancer Hospital, 38 Guangji Road, 310022, Hangzhou, People's Republic of China

Tel $+8657 \mid 88122088$

Fax +86 57I 88I2 2088

Email helen-0407@।63.com 
A

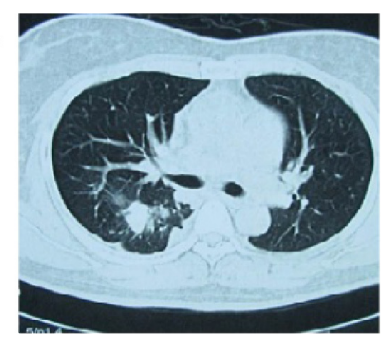

D

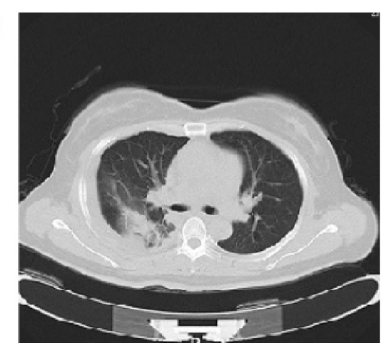

B

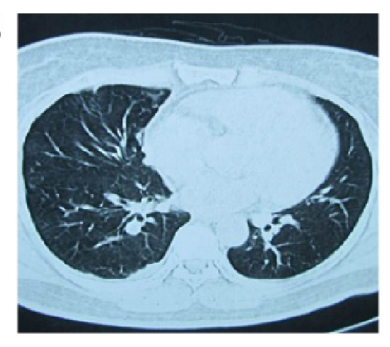

E

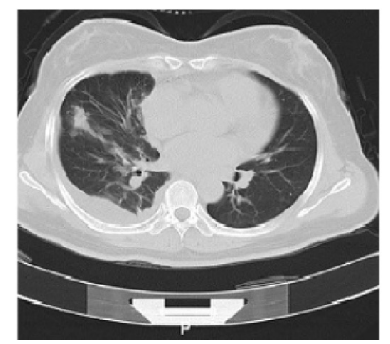

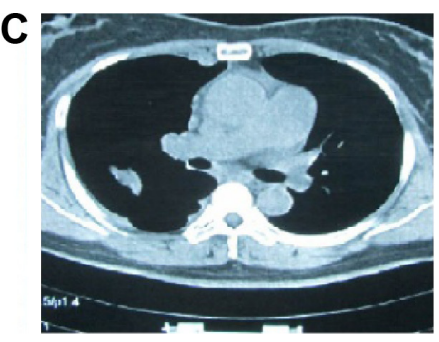

$\mathbf{F}$

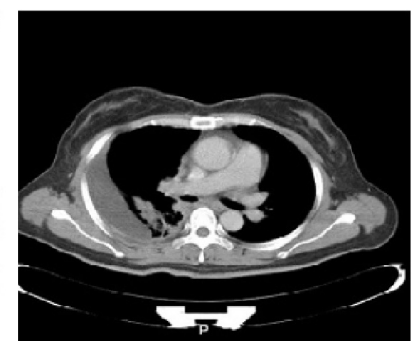

Figure I CT scans show: before crizotinib therapy (A-C); CT of the chest revealed the recurrence after 2 months of crizotinib (D-F). Abbreviation: CT, computed tomography.

pleural metastasis (T2aNxM1a stage IV) (Figure 1A-C). A pathological diagnosis of ADC cell was performed using needle core biopsy. Hematoxylin and eosin (H\&E) staining showed a typical morphology of ADC cell (Figure 2A). Immunohistochemistry (IHC) analysis demonstrated positivity in thyroid transcription factor 1 (TTF-1), cytokeratin 7 (CK7), and Napsin A, and negativity in cytokeratin (CK) 5/6 and P63. Tumor tissue was detected wild-type of EGFR variants by ARMS (AmoyDx, Xiamen, China). $A L K$ gene rearrangement was detected by fluorescence in situ hybridization (FISH), the split-apart signals for $A L K$ gene translocation was 21\% (Figure 2B). First, the patient underwent crizotinib treatment $(250 \mathrm{mg} /$ bid, orally) from June 2014 to August 2014. The adverse reaction of nausea could be tolerated. However, this treatment showed no efficacy. Chest CT scan images demonstrated increase in tumor size and metastases (Figure 1D-F). According to the Response
Evaluation Criteria in Solid Tumors (RECIST) guidelines (version 1.1), such tumor response to crizotinib was classified as progressive disease. As second-line chemotherapy, the patient was administrated the four cycles of chemotherapy regimens of pemetrexed $500 \mathrm{mg} / \mathrm{m}^{2} \mathrm{D} 1$ (the first day that the patients begin to receive chemotherapy) and carboplatin (area under the curve $[\mathrm{AUC}]=5 \mathrm{D} 1-3$ [the patient receives chemotherapy from the first day to the third day]) from August 2014 to December 2014. The efficacy was stable disease (SD) (15\% decreased). Unfortunately, during routine examination, the presence of pleural effusion in right lung on CT scan (Figure 3A-C) indicated cancer progression in May 2015. The pleural effusion could not be controlled after pleural effusion drainage (Figure 3D-F). Then deletion in exon 19 was found by next-generation sequencing (NGS) in plasma (geneseeq one, Nanjing, China) (Figure 4) and other mutations were not harbored such as other EGFR
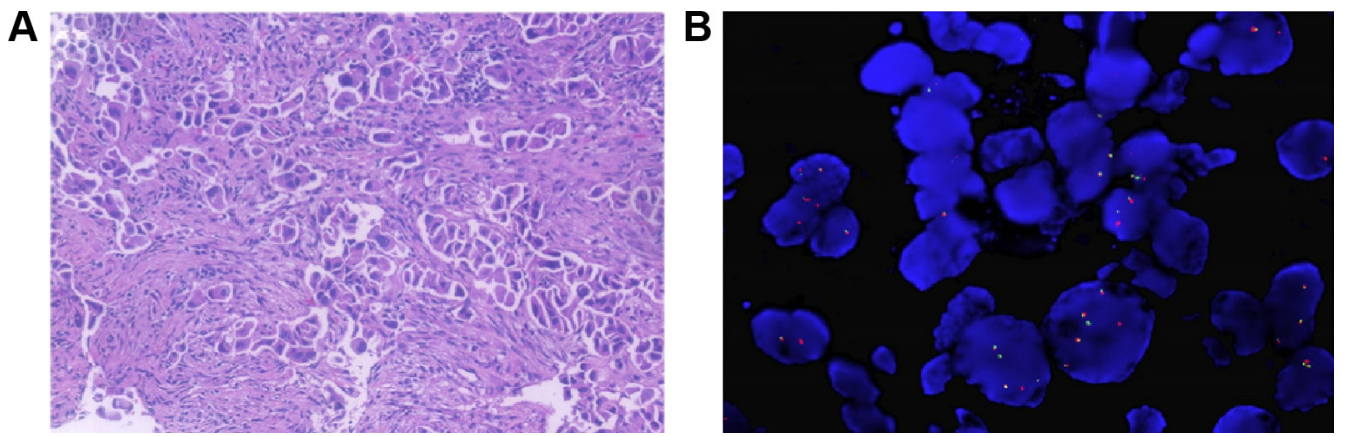

Figure 2 Needle biopsy showed a poorly differentiated carcinoma $(\mathrm{HE}, \times 200)(\mathbf{A})$ and FISH analysis of the lung tumor specimen revealed cells with characteristic ALK translocation (B).

Abbreviations: ALK, anaplastic lymphoma kinase; FISH, fluorescence in situ hybridization; HE, hematoxylin and eosin. 
A

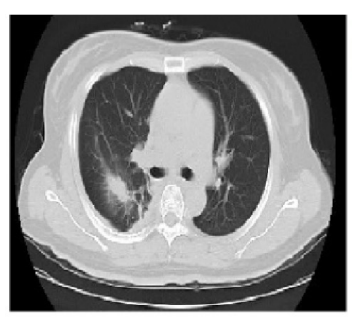

D

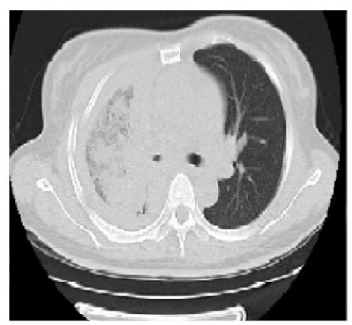

G

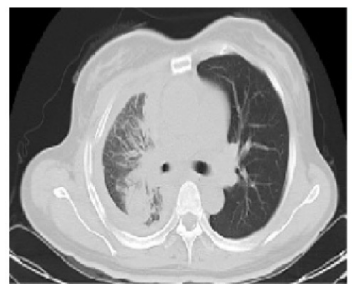

B

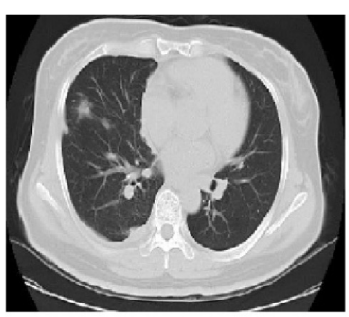

E

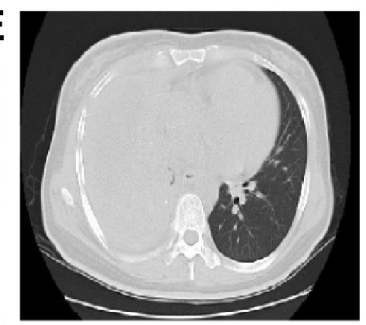

H

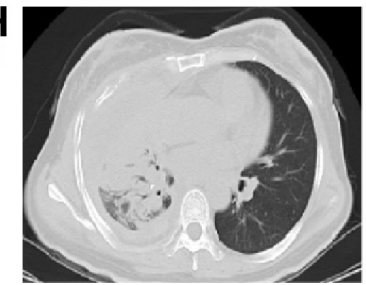

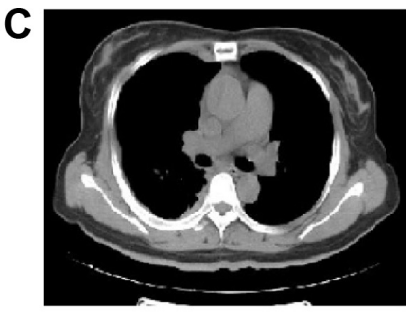

F
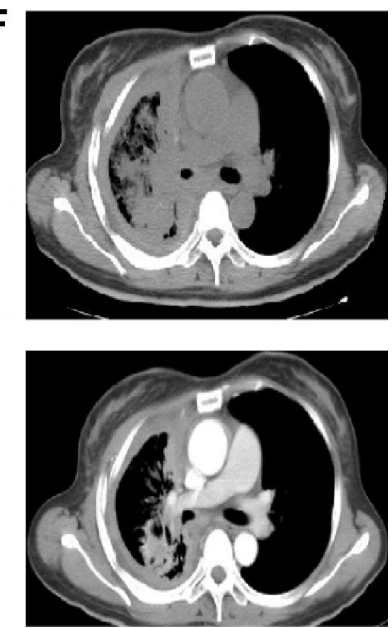

Figure 3 CT scans show: after the course of chemoradiotherapy $(\mathbf{A}-\mathbf{C})$; CT of the chest revealed the recurrence after the course of chemoradiotherapy (D-F); CT scan of chest after I month of icotinib treatment (G-I).

Abbreviation: $\mathrm{CT}$, computed tomography.

mutations, B-cell lymphoma 2 (BCL2)-like 11 deletion (BIM), ALK-fusion or MET amplification. The NGS assay used the HisSEquation 4000 to detect mutations (Illumina, San Diego, CA, USA). Then the patient underwent icotinib treatment (125 mg/tid, orally) in June 2015. After 1 month, chest CT scan images demonstrated decrease in tumor size (Figure 3G-I). The response was considered as partial response. During treatment with icotinib, the abnormal hepatic and renal function after administration were not found. There were no treatment-related adverse events

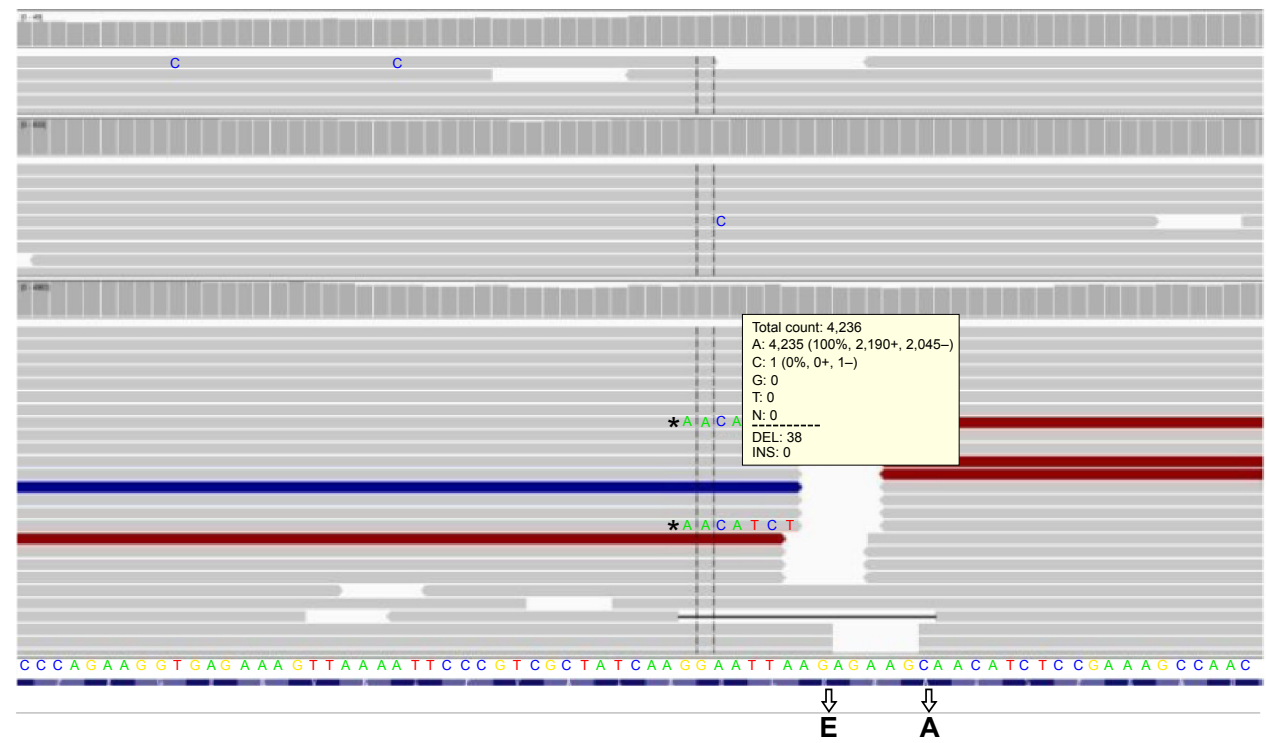

Figure 4 EGFR Exon 19 deletion (E746-A750del) in next-generation sequencing in plasma (the blank region expressed base deletion and at the bottom of bull lines indicated $E$ to $A$ deletion).

Notes: *A guidance function. The dark gray region represents an expanding fold.

Abbreviation: EGFR, epidermal growth factor receptor. 
including gastrointestinal reaction, and rash. So far, after 2 months, the disease is still stable.

\section{Discussion}

NSCLCs with ALK rearrangement are highly sensitive to the ALK kinase inhibitor crizotinib. ${ }^{8}$ Unfortunately, cases of resistance to crizotinib soon appear in NSCLC patients. Acquired resistance mechanisms to crizotinib with ALK rearranged in NSCLC have been described. ${ }^{9,10}$ The mechanisms of acquired resistance to ALK inhibitors can be divided into two types: ALK dominant or ALK nondominant. ALK dominant resistance mechanisms include secondary mutations and copy number gain in the ALK gene; ALK nondominant resistance mechanisms include the activation of bypass tracks, such as EGFR, KRAS, KIT, MET, and IGF-1R. ${ }^{11}$ Doebele et $\mathrm{al}^{12}$ reported a patient with ALK rearrangement was detected EGFR exon 21 mutation after 61 days on crizotinib. To date, there is a lack of reports to demonstrate the mechanisms of primary resistance to crizotinib with $A L K$-positive ADC. In our report, we experienced a rare case. Because of insufficient samples, we did not detect the initial biopsy tissue by NGS. On the other hand, the ARMS assay is sensitive, routinely being able to detect at least $1 \%{ }^{13}$ the NGS method used appears not to be as sensitive as the real-time polymerase chain reaction methods. ${ }^{14}$ So, we thought the initial EGFR gene testing result would not be a false negative. After resistance to crizotinib, we suggested the patient to take a re-biopsy, but she did not want to do it. Thereby, because the patient didn't want to do a re-biopsy, it is a way to use plasma to detect if other mutations will be found by NGS. Thanks to the NGS having a higher coverage, it would become a tool to overcome the tumor heterogeneity. In reality, in some cases, re-biopsy may be too difficult to be obtained. In our report, we used NGS of the plasma to detect mutation. This is a limitation in this study. Pekar-Zlotin et al ${ }^{15}$ compared FISH, IHC, and NGS for detection of EML4-ALK rearrangement by tumor tissues in lung cancer; the sensitivity and specificity of NGS were $42.9 \%$ and $97.7 \%$, respectively, for FISH and $100 \%$ and $97.7 \%$, respectively, for IHC. So, the NGS assay to detect $E M L 4-A L K$ rearrangement from plasma is lacking in much of the clinical research and data. To date, molecular tests in advanced NSCLC patients can be performed in different biological samples, such as transbronchial biopsy, bronchial lavage, pleural fluid, and blood. Because of the difficultly of re-biopsy, it may be a promising way to detect a gene mutation in the blood. In our report, the patient was tested for the EGFR mutation and she had a response for treatment of icotinib.

In summary, our case is the first report to demonstrate a patient harboring EGFR mutation by NGS detection after primary resistance to crizotinib and response to EGFR-TKI treatment.

\section{Disclosure}

The authors report no conflicts of interest in this work.

\section{References}

1. Ettinger D, Wood D, Akerley W, et al. Non-small cell lung cancer, version 6. 2015. J Natl Compr Canc Netw. 2015;13(5):515-524.

2. Crino L, Kim D, Riely GJ, et al. Initial Phase II results with crizotinib in advanced ALK-positive non-small cell lung cancer (NSCLC): PROFILE 1005. J Clin Oncol. 2011;29:abstr: 7514.

3. Toyokawa G1, Seto T. Updated evidence on the mechanisms of resistance to ALK inhibitors and strategies to overcome such resistance: clinical and preclinical data. Oncol Res Treat. 2015;38(6):291-298.

4. Shaw AT, Kim D, Mehra R, et al. Ceritinib in ALK-rearranged nonsmall cell lung cancer. N Engl J Med. 2014;370(13):1189-1197.

5. Gadgeel SM, Gandhi L, Riely GJ, et al. Safety and activity of alectinib against systemic disease and brain metastases in patients with crizotinibresistant ALK-rearranged on-small-cell lung cancer (AF-002JG): results from the dose-finding proportion of a phase 1/2 study. Lancet Oncol. 2014;15(10):1119-1128.

6. Mayo C, Bertran-Alamillo J, Molina-Vila MA, Giménez-Capitán A, Costa C, Rosell R. Pharmacogenetics of EGFR in lung cancer: perspectives and clinical applications. Pharmacogenomics. 2012;13(7): 789-802.

7. Hu X, Han B, Gu A, et al. A single-arm, multicenter, safety-monitoring, phase IV study of icotinib in treating advanced non-small cell lung cancer (NSCLC). Lung Cancer. 2014;86(2):207-212.

8. Shaw A, Yeap B, Solomon BJ, et al. Effect of crizotinib on overall survival in patients with advanced non-small-cell lung cancer harbouring ALK gene rearrangement: a retrospective analysis. Lancet Oncol. 2011; 12(11):1004-1012.

9. Camidge DR, Doebele RC. Treating ALK-positive lung cancer - early success and future challenges. Nat Rev Clin Oncol. 2012;9(5): 268-277.

10. Choi YL, Soda M, Yamashita Y, et al; ALK Lung Cancer Study Group. EML4-ALK mutations in lung cancer that confer resistance to ALK inhibitors. N Engl J Med. 2010;363(18):1734-1739.

11. Katayama R, Shaw AT, Khan TM, et al. Mechanisms of acquired crizotinib resistance in ALK-rearranged lung cancers. Sci Transl Med. 2012;4(120):120-127.

12. Doebele R, Pilling A, Aisner D, et al. Mechanisms of resistance to crizotinib in patients with ALK gene rearranged non-small cell lung cancer. Clin Cancer Res. 2012;18(5):1472-1482.

13. Ellison G, Donald E, McWalter G, et al. A comparison of ARMS and DNA sequencing for mutation analysis in clinical biopsy samples. $J$ Exp Clin Cancer Res. 2010;29(132):1-8.

14. Tuononen K, Mäki-Nevala S, Sarhadi VK, et al. Comparison of targeted next-generation sequencing (NGS) and real-time PCR in the detection of EGFR, KRAS, and BRAF mutations on formalin-fixed, paraffinembedded tumor material of non-small cell lung carcinoma-superiority of NGS. Genes Chromosomes Cancer. 2013;52(5):503-511.

15. Pekar-Zlotin M, Hirsch FR, Soussan-Gutman L, et al. Fluorescence in situ hybridization, immunohistochemistry, and next-generation sequencing for detection of EML4-ALK rearrangement in lung cancer. Oncologist. 2015;20(3):316-322. 
OncoTargets and Therapy

\section{Publish your work in this journal}

OncoTargets and Therapy is an international, peer-reviewed, open access journal focusing on the pathological basis of all cancers, potential targets for therapy and treatment protocols employed to improve the management of cancer patients. The journal also focuses on the impact of management programs and new therapeutic agents and protocols on

patient perspectives such as quality of life, adherence and satisfaction. The manuscript management system is completely online and includes a very quick and fair peer-review system, which is all easy to use. Visit http://www.dovepress.com/testimonials.php to read real quotes from published authors.

Submit your manuscript here: http://www.dovepress.com/oncotargets-and-therapy-journal 